\title{
Trombofilia hereditária: um caso, várias questões
}

Ricardo Peixoto Lima,* Margarida Moreira*

\begin{abstract}
RESUMO
Introdução: A mutação G20210A do gene da protrombina ou do fator $V$ de Leiden estão associadas a $50-60 \%$ dos casos de trombofilia hereditária. A prevalência da mutação G20210A varia entre 0,7 e 4,0\%, condicionando um aumento de cerca de 2,8 vezes do risco tromboembólico, mas o seu papel não é claro na recorrência. Mulheres portadoras desta mutação têm maior risco de evento trombótico com a toma de contracetivos orais combinados (COC) e na gravidez. O objetivo deste caso é sensibilizar para os fatores que concorreram para o risco tromboembólico numa mulher jovem e as implicações a nível individual e familiar.

Descrição do caso: Mulher de 25 anos, pertencente a uma família nuclear, na fase I do ciclo de Duvall, sem antecedentes familiares relevantes, com antecedentes pessoais de tromboembolismo pulmonar (TEP) após início de COC, na sequência do qual se identificou mutação heterozigótica G20210A do gene da protrombina. Cumpriu hipocoagulação durante os seis meses seguintes. Tem uma irmã de 22 anos a considerar iniciar contraceção. Há cerca de um ano, por planear engravidar, foi enviada a consulta de apoio à fertilidade, tendo indicação para ser reencaminhada caso engravidasse. A 29 de janeiro de 2015 veio à consulta por suspeita de gravidez, confirmando-se gestação, pelo que foi de imediato referenciada para consulta de gravidez de risco hospitalar urgente. A 15 de fevereiro de 2015 deu entrada no serviço de urgência por dispneia de início súbito, com diagnóstico de TEP e foi medicada com enoxaparina, que mantém no puerpério. A gravidez decorreu sem outras intercorrências com parto eutócico às 40 semanas. A recém-nascida é saudável.

Comentário: Este caso coloca várias questões ao médico de família, sobretudo a relacionada com a oportunidade de início de heparina de baixo peso molecular no início da gravidez numa mulher com esta mutação e, por outro lado, a discussão sobre o rastreio da mutação em familiares assintomáticos.
\end{abstract}

Palavras-chave: Trombofilia Hereditária; Contracetivos; Gravidez; Tromboembolismo Venoso.

\section{INTRODUÇÃO}

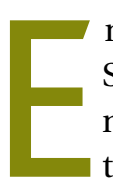

m Portugal, segundo o Inquérito Nacional de Saúde $2005 / 2006,85,1 \%$ da população feminina em idade fértil utilizava algum método contracetivo. Entre estas mulheres, o contracetivo oral era o método de eleição em $65,6 \%$ dos casos. ${ }^{1}$

Vários fatores condicionam a escolha do método contracetivo, pelo que a opção deve ser partilhada e ter em conta riscos e contraindicações. ${ }^{2}$ No caso dos contracetivos orais combinados (COC) em particular, uma revisão da Cochrane concluiu que todos apresentavam um risco aumentado de trombose venosa, que depende não só da dose de estrogénio mas também do tipo de progestativo usado (maior com os de terceira, como o gestodeno, e quarta gerações). ${ }^{3}$ Para o anel vaginal e

*Médicos Internos de Medicina Geral e Familiar, USF das Ondas para o adesivo transdérmico, que contêm progestativos de terceira geração, os estudos são limitados. Relativamente ao adesivo, comparativamente a COC contendo progestativos de segunda geração, alguns estudos demostraram um maior risco tromboembólico, enquanto outros mostraram um risco similiar. No que diz respeito ao anel, os dados são ainda mais escassos e um estudo americano mostrou um risco semelhante ao dos COC na sua generalidade. ${ }^{4}$

Por outro lado, as trombofilias são condições também associadas a um aumento do risco de tromboembolismo venoso (TEV). Entre estas, a mutação G20210A do gene da protrombina e a mutação do fator V de Leiden são as mais frequentes e estão associadas a 50-60\% dos casos de trombofilia hereditária. ${ }^{5} \mathrm{Um}$ estudo multicêntrico europeu identificou uma prevalência da mutação G20210A do gene da protrombina na população 
geral entre 0,7 e 4,0\% ${ }^{6}$ Esta mutação condiciona um aumento do risco tromboembólico de cerca de 2,8 vezes (que varia consoante os estudos); ${ }^{7}$ contudo, o seu papel não é claro na recorrência dos eventos. Nestes doentes, com risco trombótico de base aumentado, é geralmente necessária uma condição adicional com potencial trombótico para despoletar um evento tromboembólico, como uma neoplasia, cirurgia, imobilização, viagens de longo curso, toma de COC ou gravidez/pósparto, o que reforça a etiologia multifatorial do TEV. ${ }^{8}$

Tendo em conta que, no nosso país, a maioria das mulheres é vigiada em consulta de planeamento familiar (cerca de $77 \%$ ), ${ }^{1}$ em grande parte pelo seu médico de família, o objetivo deste caso é sensibilizar para os fatores que concorreram para eventos tromboembólicos numa mulher jovem, nomeadamente o uso de COC, a trombofilia por mutação heterozigótica G20210A do gene da protrombina e a gravidez, aos quais o médico de família deve estar atento.

\section{DESCRIÇÃO DO CASO}

Expõe-se o caso de uma mulher, FRB, 25 anos, caucasiana, natural e residente em Navais, com o $12 .^{\circ}$ ano de escolaridade (curso de animadora sociocultural), auxiliar de educação num infantário, pertencente a uma família nuclear na fase I do ciclo de Duvall e com classe média de Graffar. Nega medicação habitual, consumo de tóxicos (álcool, tabaco ou drogas ilícitas) ou alergias conhecidas. Teve menarca aos 13 anos; sem história de abortamentos, nulípara.

Na história familiar reporta apenas um caso de acidente vascular isquémico em prima de segundo grau do lado materno; sem outros antecedentes relevantes (Figura 1).

Nos antecedentes pessoais regista-se excesso de peso e veias varicosas com classificação CEAP 1 . Além disso, aos 17 anos, um dia após ter iniciado COC $(0,02 \mathrm{mg}$ etinilestradiol e $0,075 \mathrm{mg}$ gestodeno), desenvolveu um quadro de instalação súbita de dispneia, palpitações e dor torácica. Na sequência desse episódio recorreu ao hospital da área de residência, tendo tido alta medicada para intercorrência respiratória, com cefuroxima $250 \mathrm{mg}$ e inalador com $250 \mathrm{mg}$ de propionato de fluticasona e 50mg de salmeterol de 12/12h. Três dias depois dirigiu-se à urgência de um hospital privado, onde fez radiografia pulmonar e teve alta com indicação de manter a medicação prévia. Por agravamento progressivo do quadro ao longo de uma semana recorreu novamente ao hospital da área de residência e, por suspeita de tromboembolismo pulmonar (TEP), foi transferida para o Hospital Pedro Hispano onde foi confirmado o diagnóstico de TEP extenso (Figura 2), tendo ficado internada. Teve alta hipocoagulada com acenocumarol, que manteve durante seis meses, com indicação de suspender o COC e de utilizar método de barreira como contracetivo. Foi acompanhada em consulta de medicina interna, tendo realizado estudo protrombótico que identificou uma mutação heterozigótica G20210A do gene da protrombina.

Iniciou contraceção com implante progestativo subcutâneo após terminar hipocoagulação terapêutica. Suspendeu este método aos 25 anos porque pretendia engravidar e, por isso, foi enviada pela médica de família a consulta de apoio à fertilidade do hospital de referência. Foi decidido não iniciar terapêutica tromboprofilática. A doente teve alta da consulta com indicação de ser referenciada a consulta de gravidez de risco, logo que engravidasse, para ponderar profilaxia. Iniciou ácido fólico.

A 19 de janeiro de 2015 veio à consulta aberta da sua médica de família, com queixas de mal-estar geral, amenorreia de cerca de três meses e tensão mamária. Cerca de um mês antes tinha realizado teste imunológico de gravidez (TIG), que foi negativo. Na consulta repetiu TIG, que foi positivo, e imediatamente foi pedida consulta urgente de gravidez de risco e de rastreio prénatal e iniciada vigilância da gravidez.

Por dor tipo dismenorreia ligeira e hemorragia escassa recorreu ao serviço de urgência (SU) do Centro Hospitalar de São João (CHSJ) a 31 de janeiro de 2015, constatando-se gravidez compatível com nove semanas de gestação, com embrião viável. Teve alta, mostrando interesse em passar a ser seguida em consulta de obstetrícia, risco trombótico, deste hospital. A 15 de fevereiro de 2015 recorreu novamente ao SU do CHSJ por dispneia de início súbito. Tendo em conta a contraindicação da tomografia computorizada (TC) na gravidez, foi feito um diagnóstico presuntivo de TEP pela alta probabilidade do mesmo: antecedentes da doente, gravidez, D-dímeros e pressão sistólica da artéria pulmonar elevados, eletrocardiograma com padrão S1T3 e taquicardia sinusal. 


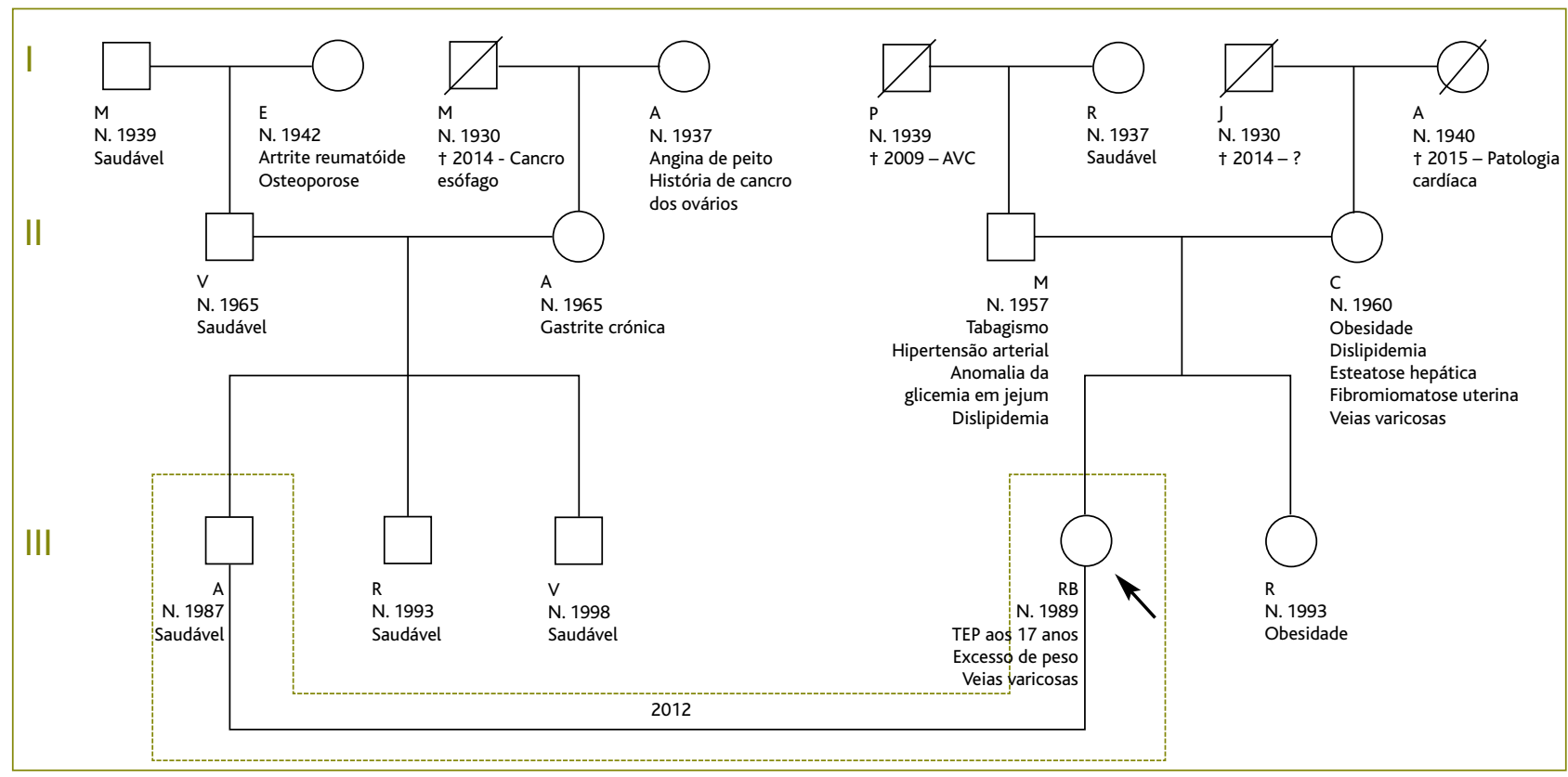

Figura 1. Genograma familiar. Aguçadoura, 04/05/2015 (note-se que não foram apresentados os tios maternos e paternos por dificuldade gráfica e por não acrescentarem dados importantes ao caso).

\begin{tabular}{|l|}
\hline Legenda: \\
$\bigcirc$ Mulher $\varnothing$ Mulher falecida \\
$\square$ Homem $\square$ Homem falecido \\
$\square$ Casamento \\
Probando \\
N. - nascimento \\
$\dagger-$ morte
\end{tabular}

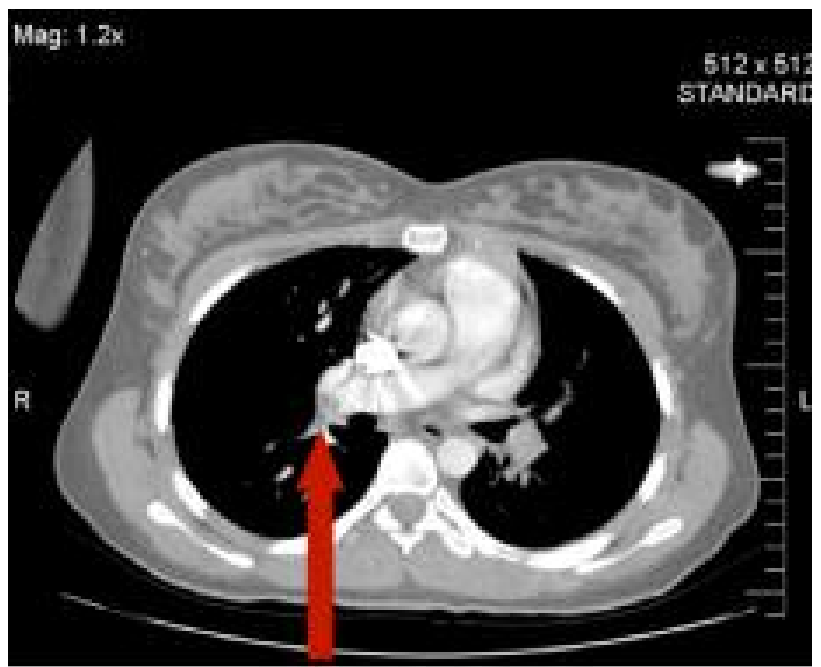

Figura 2. Imagem de TC contrastada do tromboembolismo pulmonar (mais evidente à direita - seta) em 26/08/2006.
Após internamento ficou medicada com enoxaparina (80mg de 12/12h).

A utente foi seguida em obstetrícia do CHSJ e na Unidade de Saúde Familiar (USF) até ao final da gravidez que, de resto, decorreu sem intercorrências, assim como o parto, de termo, eutócico, às 40 semanas de gestação, sem necessidade de indução. A recém-nascida nasceu com 3.485g e é saudável. Mãe e filha encontram-se bem, sendo que a primeira mantém para já a administração subcutânea de enoxaparina.

Numa das consultas de seguimento com a sua médica de família, acompanhada pela irmã, referiu que lhe foi sugerido no hospital o rastreio da mutação na irmã de 22 anos, que pretendia iniciar contraceção, tendose encaminhado a mesma para consulta de genética, a qual aguarda. 


\section{COMENTÁRIO}

Na perspetiva do médico de família, este caso mostra-se relevante por vários motivos, nomeadamente por apresentar a situação de uma mulher com dois episódios de TEP que ocorreram em contexto de trombofilia por mutação heterozigótica G20210A do gene da protrombina associada a condições de hiperestrogenismo.

Deste modo, proporciona uma discussão acerca de várias questões:

1. Como prever o risco trombótico numa mulher que inicia um contracetivo hormonal combinado (CHC)?

A incidência do TEV é de cerca de dois a três por cada mil indivíduos. Assim, apesar dos CHC aumentarem o risco relativo de $\mathrm{TEV}$, em termos de risco absoluto o efeito não é tão notório e, na maior parte das vezes, os CHC parecem ser apenas o precipitante do evento, não tendo qualquer efeito deletério neste aspeto em mulheres saudáveis. ${ }^{9-10}$

Por este motivo, antes de se iniciar um CHC numa mulher deve ser avaliado o seu risco trombótico, questionando acerca da história pessoal e familiar (sobretudo em familiares de primeiro grau) de eventos tromboembólicos, sendo que esta última tem uma sensibilidade e um valor preditivos muito baixos, mesmo em populações de alta prevalência. ${ }^{9-10} \mathrm{Um}$ evento anterior de TEV constitui uma contraindicação absoluta para o uso de CHC, assim como a imobilização prolongada e o estado de portador de trombofilia. ${ }^{4,10}$ Contudo, o rastreio universal de trombofilias antes de se iniciar um CHC não está recomendado, não se tendo mostrado custo-efetivo, especialmente no caso das trombofilias minor, com risco trombótico moderado (como é o caso da mutação heterozigótica G20210A do gene da protrombina), devendo ser efetuado apenas em situações selecionadas de alto risco. ${ }^{11}$

Outros fatores que devem ser avaliados antes de iniciar um CHC incluem a idade, a exposição a cirurgias major, o índice de massa corporal, os hábitos tabágicos e o pós-parto imediato, assim como a presença de comorbilidades como hipertensão não controlada, doença cardiovascular, diabetes com complicações, obesidade grau II ou III, doença hepática, enxaqueca e os fármacos concomitantes. ${ }^{2,4}$

Esta mulher não tinha quaisquer fatores de risco que contraindicassem o uso de $\mathrm{CHC}$ e que fizessem prever a ocorrência de um TEV.

2. Em que situações deverão ser rastreadas as trombofilias hereditárias?

Tendo em conta o elevado custo do estudo laboratorial, o rastreio deve obedecer a critérios. O teste de indivíduos selecionados pode fornecer uma indicação do risco de recorrência após a interrupção da hipocoagulação terapêutica. Assim, este estudo parece ser mais profícuo em indivíduos que tiveram um evento de TEV antes dos 50 anos, na ausência de fatores de risco transitórios, episódios recorrentes ou trombose venosa em lugares atípicos (mesentérica, esplénica, hepática, renal ou cerebral) e em mulheres com história obstétrica adversa. $^{12}$

Mais controverso é o rastreio em indivíduos assintomáticos e sobretudo em familiares de doentes com trombofilia, em que o objetivo será prevenir a exposição ou instituir profilaxia em situações de risco. Alguns autores defendem o seu rastreio se tiver sido detetada uma mutação específica num familiar de primeiro grau. ${ }^{12}$ Por outro lado, outros não o recomendam, ${ }^{12}$ sobretudo em mulheres que pretendam iniciar contraceção ou terapêutica hormonal de substituição, advogando que, independentemente do resultado do rastreio, devem sempre ser considerados métodos alternativos se houver antecedentes familiares de TEV. ${ }^{13} \mathrm{O}$ estudo European Prospective Cohort on Thrombophilia (EPCOT) sugere que em mutações como a G20210A do gene da protrombina, tendo em conta que a sua contribuição num primeiro episódio de TEV idiopático é baixa, não deve haver lugar ao rastreio por rotina dos familiares dos portadores. No entanto, propõe que este seja considerado caso o indivíduo entre numa fase em que o risco se preveja longo, como na gravidez ou diagnóstico de malignidade. ${ }^{14}$

Assim, neste caso, rastrear ou não rastrear a irmã da utente seriam ambas opções lícitas, desde que esta fosse devidamente esclarecida acerca das vantagens e desvantagens do rastreio, de modo a fazer uma escolha informada. Caso se optasse por um contracetivo progestativo ou não hormonal (que seriam preferíveis neste caso já que esta apresenta um potencial fator de risco adicional: obesidade), poder-se-ia prescindir do rastreio. Por outro lado, perante a hipótese de gravidez, este poderá ser vantajoso. Ainda que não existam 
recomendações universais acerca de quem rastrear, o American College of Obstetricians and Gynaecologists sugere fazê-lo quando os resultados possam influenciar a atitude terapêutica durante a gravidez. ${ }^{15}$

3. Que situações devem motivar início de tromboprofilaxia nos portadores da mutação?

A ocorrência de um TEV aumenta a probabilidade de um segundo evento, mas a ocorrência da mutação por si só não parece justificá-lo. Desta forma, sugere-se tromboprofilaxia em caso de gravidez se episódio prévio de TEV ou se houver fatores de risco adicionais (o mesmo se propõe para as cirurgias ou viagens longas) ou complicações adversas em gestação anterior. Por outro lado, esta deve ser mantida ad eternum se tiverem existido duas ou mais tromboses venosas idiopáticas, um episódio espontâneo que ameaçou a vida ou que ocorreu num local incomum ou uma trombose idiopática com existência de mais que uma mutação protrombótica. ${ }^{16-18}$

A presença da mutação também não justifica prolongamento do tempo de tratamento de um evento agudo para além dos três a seis meses, devendo este ser determinado pela persistência do fator desencadeante. ${ }^{17-18}$

4. Neste caso, qual seria o timing adequado para início de profilaxia? Durante quanto tempo deveria ser mantida?

Nas mulheres com mutações com risco trombótico moderado, o risco de TEV associado à gravidez ou pósparto é superior àquele associado ao uso de $\mathrm{CHC} .{ }^{11} \mathrm{As}-$ sim, esta mulher, por já ter tido um episódio de TEV associado à toma de CHC, teria indicação para iniciar tromboprofilaxia com heparina de baixo peso molecular desde o início da gravidez até seis a oito semanas após o parto, ${ }^{18}$ tendo-se falhado, no caso, uma janela de oportunidade que favoreceu a ocorrência de um segundo TEP.

5. Que outras implicações poderá ter esta mutação para esta mulher e que precauções tomar?

Durante uma gravidez, o TEV poderá não ser a única consequência da presença da mutação, podendo estar também associada a perda fetal tardia, perdas fetais recorrentes, parto pré-termo, descolamento de placenta, pré-eclâmpsia grave e restrição de crescimento intrauterino. ${ }^{19}$

Esta mulher teve dois episódios em que foi possível identificar os eventos despoletantes, ambos em contexto de hiperestrogenismo, pelo que o que está preconizado é que não é necessário manter hipocoagulação profilática indefinidamente, mas considerá-la sempre que se prevejam fatores de risco adquiridos que aumentem o risco de TEV. Isto significa que contraceção, gravidezes futuras, cirurgias, viagens e instituição de terapêutica hormonal na menopausa devem ser cuidadosamente planeadas. Não obstante, deverá ser sempre esclarecida a mulher sobre o risco de cada intervenção de modo a que esta faça a sua opção.

Relativamente ao método contracetivo a usar no futuro, os poucos estudos existentes referem um risco negligenciável de TEV associado ao uso de progestativo oral ou injetável e ausência de risco aumentado com o uso de implante subcutâneo ou dispositivo intrauterino. ${ }^{4}$ Portanto, estes últimos, tal como o método de barreira, devem ser os métodos preferidos numa mulher com história prévia de TEV ou de trombofilia, ${ }^{20}$ como é o caso desta mulher.

Esta mulher jovem compreendeu a importância da sua condição e as possíveis implicações da mesma no futuro, tendo contado sempre com o apoio da família. Consequentemente, aderiu sempre à medicação prescrita, referindo apenas em relação à hipocoagulação a ocorrência de equimoses fáceis, mas que não interferiam com a sua qualidade de vida. Perante o segundo evento mostrou-se receosa relativamente à possibilidade de ter de manter hipocoagulação ad eternum, mas foi desde logo tranquilizada pela obstetra assistente de que essa hipótese seria pouco provável, vivendo serenamente a sua gravidez.

Este relato de caso reúne duas situações muito frequentes no consultório do médico de família, nomeadamente o início de contraceção e o acompanhamento de uma gravidez e as implicações da existência de uma trombofilia, neste caso, da mutação G20210A no desfecho de cada uma delas e os cuidados a ter, contribuindo para uma melhoria da prática clínica.

\section{REFERÊNCIAS BIBLIOGRÁFICAS}

1. Instituto Nacional de Estatística, Instituto Nacional de Saúde Dr. Ricardo Jorge. Inquérito nacional de saúde 2005/2006. Lisboa: INSA; 2009.

2. Pacheco A, Machado Al, Costa AR, Lanhoso A, Cruz E, Palma F, et al. Estoril: Sociedade Portuguesa de Ginecologia; Sociedade Portuguesa da Contraceção; Sociedade Portuguesa de Medicina da Re- 
produção; 2011.

3. de Bastos M, Stegeman BH, Rosendaal FR, Van Hylckama Vlieg A, Helmerhorst FM, Stijnen T, et al. Combined oral contraceptives: venous thrombosis. Cochrane Database Syst Rev. 2014;(3):CD010813.

4. Faculty of Sexual \& Reproductive Healthcare. Venous thromboembolism (VTE) and hormonal contraception: statement. London: Royal College of Obstetricians \& Gynaecologists; 2014. Available from: http://www.fsrh.org/pdfs/FSRHStatementVTEandHormonalContraception.pdf

5. Poort SR, Rosendaal FR, Reitsma PH, Bertina RM. A common genetic variation in the 3 -untranslated region of the prothrombin gene is associated with elevated plasma prothrombin levels and an increase in venous thrombosis. Blood. 1996;88(10):3698-703.

6. Rosendaal FR, Doggen CJ, Zivelin A, Arruda VR, Aiach M, Siscovick DS, et al. Geographic distribution of the $20210 \mathrm{G}$ to A prothrombin variant. Thromb Haemost. 1998;79(4):706-8.

7. Bauer KA. The thrombophilias: well-defined risk factors with uncertain therapeutic implications. Ann Intern Med. 2001;135(5):36773.

8. Bauer KA. Prothrombin gene mutation: thrombotic risk and diagnosis. UpToDate; 2014 [updated 2015 Sep; cited 2015 Mar]. Available from: http://www.uptodate.com/contents/prothrombingene-mutation-thrombotic-risk-and-diagnosis

9. Middeldorp S. Oral contraceptives and the risk of venous thromboembolism. Gend Med. 2005;2 Suppl A:S3-9.

10. Grimes DA, Stuart GS, Levi EE. Screening women for oral contraception: can family history identify inherited thrombophilias? Obstet Gynecol. 2012;120(4):889-95.

11. Blanco-Molina Á. Oral contraception in women with mild thrombophilia: what have we learned recently? Thromb Res. 2012;130 Suppl 1:S16-8.

12. Lima J, Borges A. Rastreio de trombofilias [Thrombophilia screening]. Bol SPHM. 2012;27(4):5-11. Portuguese

13. Baglin T, Gray E, Greaves M, Hunt BJ, Keeling D, Machin S, et al. Clinical guidelines for testing for heritable thrombophilia. $\mathrm{Br} J \mathrm{Hae}-$ matol. 2010;149(2):209-20.

14. Spencer FA, Goldberg RJ.Asymptomatic thrombophilia: a family affair. J Thromb Haemost. 2005;3(3):457-8.

15. American College of Obstetricians and Gynecologists Women's Health Care Physicians. ACOG Practice Bulletin No. 138: inherited thrombophilias in pregnancy. Obstet Gynecol. 2013;122(3):70617.

16. Bauer KA. Management of inherited thrombophilia. UpToDate [updated 2014 Mar; cited 2015 Mar]. Available from: http://www.uptodate.com/contents/management-of-inherited-thrombophilia

17. Kearon C, Crowther M, Hirsh J. Management of patients with hereditary hypercoagulable disorders. Annu Rev Med. 2000;51:16985.

18. Lima J. Trombofilias e gravidez [Thrombophilia and pregnancy]. Bol SPHM. 2006;21(3):6-23. Portuguese

19. Fonseca AG. As trombofilias hereditárias na grávida: do risco trombótico ao sucesso da gravidez [Hereditary thrombophilia and pregnancy: thrombotic risk and pregnancy outcome]. Acta Med Port. 2012;25(6):433-41. Portuguese

20. Maxwell WD, Jacob M, Spiryda LB, Bennett CL. Selection of contraceptive therapy for patients with thrombophilia: a review of the evidence. J Womens Health (Larchmt). 2014;23(4):318-26.

\section{CONFLITO DE INTERESSES}

Os autores declaram não ter conflitos de interesses.

\section{ENDEREÇO PARA CORRESPONDÊNCIA}

Margarida Moreira

R. da Praia, n.` 186, Fieiro - Aguçadoura, 4495-031 Póvoa de Varzim

E-mail: mmargmoreira@gmail.com

Recebido em 02-06-2015

Aceite para publicação em 08-10-2015 


\section{ABSTRACT}

\section{HEREDITARY THROMBOPHILIA: ONE CASE, SEVERAL ISSUES}

Introduction: Over 50\% of cases of hereditary thrombophilia are associated with the either the G20210A prothrombin gene mutation or factor $\vee$ Leiden. The prothrombin G20210A mutation is present in $0.7-4 \%$ of the general population and triples the risk of thromboembolism. The role of this mutation in the recurrence of the condition is unclear. Women with this mutation have an increased risk of thrombotic events during pregnancy and with oral contraceptives. The aim of this report is to raise awareness of the factors that contributed to thromboembolism in a young woman and to discuss the implications for the individual and the family.

Case description: A 25-year-old female in a nuclear family at stage I of the Duvall cycle, without a family history of embolism, developed a pulmonary thromboembolism (PT) after receiving a combined oral contraceptive. The G20210A prothrombin gene heterozygous mutation was identified. She was put on anticoagulant therapy for six months. One year ago she expressed a desire to conceive and was referred for preconception counseling at a local hospital. She was advised to return to hospital in case of pregnancy. Following confirmation of pregnancy by her family doctor at the end of January 2015, the patient was immediately referred to the hospital for a high-risk pregnancy consultation. In February she was admitted to the emergency department with the sudden onset of dyspnea and was diagnosed with a PT. Enoxaparin therapy was started and continued postpartum. There were no other complications and a healthy baby was delivered at 40 weeks of gestation by a normal delivery. The patient has a 22-year-old sister who is considering starting contraception.

Comment: This case highlights the importance of starting low molecular weight heparin treatment in early pregnancy in women with this mutation. It also stresses the importance of screening for the mutation in asymptomatic relatives.

Keywords: Hereditary; Thrombophilia; Contraceptive Agents; Pregnancy; Venous Thromboembolism. 